\title{
El principio constitucional de la tutela judicial efectiva vulnerado por la acción de nulidad de sentencias
}

\section{The constitutional principle of the effective judicial guardians, violated by the nullity of judgment action}

\author{
Marcela Rocibel Guzmán Chávez \\ marcebel1@hotmail.com \\ Universidad Nacional de Loja, Loja \\ Ecuador \\ https://orcid.org/0000-0002-6679-0661
}

Recibido: 23 de mayo de 2019

Aprobado: 14 de junio de 2019

\begin{abstract}
RESUMEN
El actual artículo de revisión tiene como esencialidad que la celeridad para que sea un elemento fundamental en la justicia, es necesario tener reglas claras por las cuales las personas se rijan a la hora de buscar protección de sus derechos fundamentales, la vulnerabilidad de no cumplir con las pautas propuestas en los documentos legales que rigen el proceder judicial. Es así que al preocuparse de la celeridad procesal, y la inclusión de los principios procesales como la concentración, contradicción, inmediación en nuestra norma jurídica procedimental y a su vez para que se configure dicha celeridad, hizo que se olvidaran del derecho a la tutela judicial efectiva y al debido proceso que son bases fundamentales para el ejercicio de un proceso.
\end{abstract}

Descriptores: Justicia; Derecho a la justicia; Administración de la justicia; Administración pública.

\begin{abstract}
The current review article has as essential that the speed to be a fundamental element in justice, it is necessary to have clear rules by which people are governed when seeking protection of their fundamental rights, the vulnerability of not complying with the guidelines proposed in the legal documents that govern judicial proceedings. Thus, when worrying about procedural speed, and the inclusion of procedural principles such as concentration, contradiction, immediacy in our procedural legal norm and in turn to configure such speed, made them forget the right to effective judicial protection and due process that are fundamental bases for the exercise of a process.
\end{abstract}


Descriptors: Justice; Right to justice; Administration of justice; Public administration

\section{INTRODUCCIÓN}

En el Ecuador desde la asamblea constituyente que dio origen a la constitución de 2008, se ha asumido la postura del neo constitucionalismo como corriente política en el ámbito jurídico, Celi (2017), plantea que esta es:

Una idea que vincula tres pilares que forman el sostén de la edificación neoconstitucional. Nos referimos a las premisas sobre derechos humanos, justicia constitucional y Constitución. En la narrativa constitucional los derechos humanos positivizados en la Constitución constituyen el fin de la polis; tanto el Estado como la sociedad, deben orientarse a satisfacer las exigencias de los derechos reconocidos por la Constitución y el derecho internacional de los derechos humanos (p. 12).

La triada, derechos humanos, justicia constitucional y constitución, permiten que el ciudadano pueda acudir a los órganos competentes en procura de justicia expedita de acuerdo a lo establecido en las normas jurídicas establecidas en el país. La protección de la persona y el debido derecho procesal como escenario de equidad social en donde se accede a la ejecución de la celeridad como elemento promotor de justicia. Para que la celeridad sea un elemento fundamental en la justicia, es necesario tener reglas claras por las cuales las personas se rijan a la hora de buscar protección de sus derechos fundamentales, la vulnerabilidad de no cumplir con las pautas propuestas en los documentos legales que rigen el proceder judicial, vulneran sobre manera los preceptos constitucionales en defensa de la persona como eje central de la sociedad, asumiendo el precepto de la Constitución de la República del Ecuador, dispuesto en su artículo 11, numeral 4, donde se expresa a la letra: "Ninguna norma jurídica podrá restringir el contenido de los derechos ni de las garantías constitucionales".

Toda persona dentro del territorio del Ecuador en su debido derecho humano fundamental, reconocido dentro de las garantías constitucionales puede acudir a los órganos de justicia que requiera para encontrar respuesta a su necesidad o requerimiento, generándose así un "Conjunto de los actos dirigidos al fin de la actuación de la ley (respecto de un bien que se pretende garantizado por ésta en el 
caso concreto) mediante los órganos de la jurisdicción ordinaria". (Chiovenda, 1922, p. 100), proyectándose la posibilidad real que toda persona puede acceder en su derecho a la tutela judicial efectiva.

\section{Derecho procesal civil}

Permite que el ciudadano recurra en búsqueda de justicia en lo relacionado a la justicia desde el ámbito civil, promoviéndose la celeridad como medio efectivo para el cumplimiento de los preceptos constitucionales, este sentido, Herrera (2017), destaca la incorporación de la oralidad como proceso judicial el Ecuador, con esto se procura fomentar una tutela judicial efectiva, destacándose el proceso monitoreo donde se aborda lo relacionado al cumplimiento de deudas que no excedan las 50 remuneraciones, esto permite contar con mecanismos de defensa de los derechos humanos como por ejemplo: cuando una persona labora sin tener contrato por escrito, pero existe veracidad de ofrecimiento de pago por parte del patrón y se puede verificar la acción laboral, entonces la persona puede recurrir sin mayor trámite que el de su propia palabra, elemento considerado por el juez como recurso probatorio de ser sometido a juicio en donde se dictará sentencia en virtud de lo reclamado.

Desde lo planteado, se genera el proceso monitoreo, tiene como fundamento el juicio estimatorio, Quintero (2016) señala que el juramento estimatorio como:

Una medida que permite cumplir con una finalidad procesal legítima, como es desestimular pretensiones sobreestimadas 0 temerarias y el incumplimiento de esta finalidad será sancionable, si la conducta de la parte es ajena al principio de buena fe procesal, como cuando se falta a la diligencia en su labor probatoria. (p. 2).

El demandando ve protegido su derecho, por cuanto no debe exagerarse en la petición, de ese modo, tanto demandante como demandando, se encuentran dentro un proceso que evita la vulnerabilidad de sus derechos fundamentales, garantizándose un debido proceso, esto implica la puesta en práctica de la responsabilidad civil como principio articulador de derecho. Le Tourneau, Phillipe, 2006) se tiene que la responsabilidad civil es una forma de 
Obligación que, según se le mire, cumple diversos objetivos, siendo uno de ellos el de responder por un daño y reparar sus consecuencias mediante indemnización a la víctima, consistiendo que su principal propósito es la de reparar con la finalidad de generar el equilibrio entre las partes afectadas (p. 21).

Una sociedad equilibrada desde la justicia, permite garantizar celeridad procesal por cuanto se evita la anarquía como medio social de imposición de conductas desequilibrantes en la gestión judicial, promoviéndose un acercamiento hacia la justicia que impera la normativa judicial de establecer el orden producto de la exigencia de los involucrados en el procedimiento, siendo recurrente establecer principio de reciprocidad que permita fomentar la celeridad como elemento fundamental de justicia y derecho social.

\section{Derecho a un proceso sin dilaciones indebidas}

Un proceso sin dilaciones indebidas, es sinónimo de respeto a los derechos humanos consagrados en la constitución, por lo tanto, retrasar sin justificación, por negligencia o por retaliaciones en contra de la persona, se convierte en acciones perjudiciales para el establecimiento del derecho que tiene la persona a un juicio alejado de factores que puedan perjudicarle, Apolín Meza (2007), señala que:

La obtención de sentencias que pongan fin al proceso no deben ser alcanzadas a cualquier costo, es decir, vulnerando otros derechos fundamentales, pues ello alargará más aún el camino para la obtención de tema sentencia justa. Es importante, entonces, que los propios jueces y partes hagan un examen de conciencia en tomo al cumplimiento de sus deberes al interior del proceso" (p. 88)

Un derecho no puede vulnerar otro derecho, por lo tanto, al generar un proceso sin dilaciones se debe tener en cuenta cumplir con los procedimientos necesarios con la finalidad de no entorpecer el derecho a otras personas, así que si se comprueba la existencia de vicios en el proceso, se puede originar la anulación del mismo, lo cual implicaría pérdida de tiempo para el indiciado, producto de malas praxis judiciales. Oubiña Barbolla (2016), señala que "las dilaciones indebidas representan una pérdida de derechos que debe ser tenida en cuenta a la hora de fijar la pena" (p. 262), así mismo, Espín López (2017), plantea que "probablemente nadie en nuestra sociedad 
se atrevería a discutir que las dilaciones indebidas es un problema malsano para el que no se consigue el remedio apropiado" (p. 20).

El tema de las dilaciones procesales se convierte en un problema social que afecta la convivencia de las familias afectadas, siendo esto un indicador negativo para la estructuración de las premisas del buen vivir, por cuanto no puede existir calidad de vida si el sistema judicial no procesa con celeridad y pertinencia ética - judicial los casos que se encuentran en proceso, lo cual permitirá establecer una sociedad de equidad y paz.

\section{Celeridad procesal}

La celeridad procesal es un tema muy importante para la aplicación de una justicia oportuna que tanto se pregona hoy en día, hasta es parte del slogan del Consejo de la Judicatura. Ahora si bien es cierto que la Justicia puede ser oportuna por el hecho de tener administradores de justicia, y donde queda la lealtad procesal el manejo oportuno de los tramites de los procesos. El hecho de que haya más jueces no quiere decir que la celeridad procesal en algunos casos haya perdido su orientación y su finalidad. Por eso al referirnos a la celeridad procesal lo debemos hacer de una manera general y conocer doctrinariamente lo que los maestros y juristas del derecho nos han dejado como legado y como su enseñanza en tan ardua tarea como lo es el derecho.

La celeridad procesal es destacada en la constitución de la república del Ecuador, en su artículo 75, cuando se emplea que toda persona tiene acceso a la justicia, esto implica que se deben brindar las condiciones para fomentar un accionar judicial que permita a las personas gozar del derecho constitucional que prevé la realización de un juicio en condiciones que exista celeridad, evitándose retardos innecesarios que terminan por producir causas negativas al entorno social, dado que se generan fragmentaciones sociales que involucran el recrudecimiento de la violencia. Así mismo, el Art. 169 de la Constitución expresa:

El sistema procesal es un medio para la realización de la justicia. Las normas procesales consagrarán los principios de simplificación, uniformidad, eficacia, inmediación, celeridad y economía procesal, y harán 
efectivas las garantías del debido proceso. No se sacrificará la justicia por la sola omisión de formalidades.

Desde lo planteado, no debe confundirse celeridad con violación de procesos o por negligencia que lleve a desestimar la aplicación de los mecanismos establecidos para el logro de un proceso judicial eficaz. Para lograr un proceso en celeridad, es necesario tener en cuenta el Código Orgánico de la Función Judicial, también contempla, dentro de su articulado, una réplica de estos Principios establecidos en la Constitución, así tenemos:

1. Art. 18: "El sistema procesal es un medio para la realización de la justicia. Las normas procesales consagrarán los principios de simplificación, uniformidad, eficacia, inmediación, oralidad, dispositivo, celeridad y economía procesal, y harán efectivas las garantías del debido proceso. No se sacrificará la justicia por la sola omisión de formalidades"

2. Art. 20: "La administración de justicia será rápida y oportuna, tanto en la tramitación y resolución de la causa, como en la ejecución de lo decidido. Por lo tanto, en todas las materias, una vez iniciado un proceso, las juezas y jueces están obligados a proseguir el trámite dentro de los términos legales, sin esperar petición de parte, salvo los casos en que la ley disponga lo contrario.

3. Art. 127: "Las secretarias y secretarios y demás servidoras y servidores judiciales que demoraren de forma injustificada o negligente poner al despacho los expedientes de su oficina, o hacer la entrega que se les hubiere ordenado, serán destituidos"

4. Art. 129: "A más de los deberes de toda servidora o servidor judicial, las juezas y jueces, según corresponda, tienen las siguientes facultades y deberes genéricos. 3. Resolver los asuntos sometidos a su consideración con estricta observancia de los términos previstos en la ley y con sujeción a los principios y garantías que orientan el ejercicio de la Función Judicial"

5. Art. 130: "Facultades jurisdiccionales de las juezas y jueces.- Es facultad esencial de las juezas y jueces ejercer las atribuciones jurisdiccionales de acuerdo con la Constitución, los instrumentos internacionales de derechos humanos y las leyes; por lo tanto deben: ...9.- Procurar la celeridad procesal, 
sancionando las maniobras dilatorias en que incurran las partes procesales o sus abogadas y abogados.

Así los servidores públicos están comprometidos con hacer cumplir los procedimientos establecidos para la legitimación de un proceso en celeridad que permita establecer vínculos éticos en la sociedad, proyectándose un enfoque social de equidad y de respeto.

\section{El derecho a la tutela judicial efectiva}

En este sentido, Valmaña (2018), establece que:

El Estado, a través del derecho a la asistencia jurídica gratuita, mantiene una actividad instrumental dirigida a dotar de medios necesarios a quienes carecen de recursos económicos para litigar, a fin de que el derecho a la tutela judicial efectiva sea real y efectivo.

Lo cual implica que se considera que existe real tutela efectiva cuando se garantiza a los ciudadanos el acceso a la justicia, esto debe ser garantizado en principio de mantener la dignidad humana como principio fundamental de la convivencia social, Aldana Zavala \& Isea (2018), explican que esto implica "conciliar el significado de dignidad humana entre las diversas sociedades, quizás esto se visualice utópico pero puede ser el motor para promover los derechos humanos y su cumplimiento tanto por las personas como por los gobiernos" (p. 18).

Una tutela judicial efectiva implica el cumplimiento de los derechos humanos, por cuanto el principal valor del ser humano es la vida y la libertad implícita en esta, al vulnerarse la libertad por retrasos que no le competen, sino que son originándose como escenarios de malas praxis judiciales, se engloba una serie de problemáticas que afectan el desenvolvimiento individual y social de las personas, viéndose afectado su rendimiento como persona productiva, siendo este un indicador de promover la necesaria vinculación con los debidos procesos que permitan operar en dignidad de la razón humana. Zambrano Noles (2016), señala que: 
En Ecuador, la más importante transformación del sistema de administración de justicia es su constitucionalización. Ha generado cambios sustanciales relacionados con la ampliación de competencias y jurisdicción, las designaciones y nombramientos de los jueces de paz, el control de efectividad de los centros de mediación y arbitraje, la creación de la defensoría pública, la ampliación de los servicios legales gratuitos a través de consultorios jurídicos en las universidades y la implementación de la oralidad en todos los procesos.

Esto implica que el enfoque neo constitucional enarbolado por la nueva constitución, ha ido dado beneficios colectivos, en razón del establecimiento de un sistema judicial normado desde la vinculación con la población, con la finalidad de que pueda acceder a la justicia desde el entorno donde se encuentre, quedando a estudio, profundizar sobre casos puntuales donde exista retraso procesal, viéndose en detrimento la perspectiva de celeridad como principio generador de justicia y equidad en la sociedad.

\section{CONCLUSIONES}

La tutela judicial efectiva se entiende aquel derecho fundamental, de disposición legal y constitucional de todas las personas, en nuestra constitución, por lo tanto dicho derecho de estas a tener libre acceso a los Juzgados para obtener una resolución de fondo fundada en Derecho.

La imposibilidad de que se suspenda la ejecución de la sentencia es una evidencia y el vacío legal existente en nuestra norma jurídica procedimental para la aplicación de una norma, así tendremos a un juez absolutamente activo y con posibilidades por ejemplo de dictar tutela preventiva no para reparar un perjuicio sino para evitarlo, prevenirlo o evitar su continuidad.

Al preocuparse de la celeridad procesal, y la inclusión de los principios procesales como la concentración, contradicción, inmediación en nuestra norma jurídica procedimental y a su vez para que se configure dicha celeridad, hizo que se olvidaran del derecho a la tutela judicial efectiva y al debido proceso que son bases fundamentales para el ejercicio de un proceso.

Con la aprobación del Código Orgánico General de Procesos, se reducen toda la vida procesal en materias no penales a cinco procesos con los cuales se tramitarán las 
diversas contiendas jurídicas, no solo civiles sino, también laborales, administrativas, tributarias y voluntarias.

\section{REFERENCIAS CONSULTADAS}

1. Aldana Zavala, J., \& Isea, J. (2018). Derechos Humanos y Dignidad Humana. IUSTITIA SOCIALIS, 3(4), 8-23. Recuperado de http://fundacionkoinonia.com.ve/ojs/index.php/lustitia_Socialis/article/view/119 $/ 101$

2. Apolín Meza, D. (2007). El derecho a un proceso sin dilaciones indebidas. Recuperado http://revistas.pucp.edu.pe/index.php/forojuridico/search/search?simpleQuery input=Apol\%C3\%ADn+Meza\&simpleQuery=Apol\%C3\%ADn+Meza\&searchFi eld=authors

3. Celi, I. (2017). Neoconstitucionalismo en Ecuador ¿Judicialización de la política - politización de la justicia? Recuperado de http://repositorio.uasb.edu.ec/bitstream/10644/6072/1/SM213-CeliNeoconstitucionalismo.pdf

4. Constitución de la República del Ecuador (2008). Recuperado de https://www.oas.org/juridico/mla/sp/ecu/sp ecu-int-text-const.pdf

5. Espín López, I. (2017). El derecho a un proceso sin dilaciones indebidas en la práctica judicial española. Recuperado de https://revistas.um.es/analesderecho/article/view/299461/224441

6. Herrera, S. (2017). Cambios normativos en materia de procedimiento civil en el Ecuador. Recuperado de https://www.derechoecuador.com/cambiosnormativos-en-materia-de-procedimiento-civil-en-el-ecuador--

7. Le Tourneau, Phillipe (2006). La responsabilidad civil profesional. Legis. Bogotá. Colombia.

8. Oubiña Barbolla, S. (2016). Dilaciones indebidas. EUNOMÍA. Revista en Cultura de la Legalidad, 0, 250-264. Recuperado de https://erevistas.uc3m.es/index.php/EUNOM/article/view/3062/1759

9. Quintero, M. (2016). El juramento estimatorio en el Código General del Proceso. Recuperado de: https://www.ambitojuridico.com/noticias/procesal-ydisciplinario/el-juramento-estimatorio-en-el-codigo-general-del-procesob 
10. Valmaña, S. (2018). La tutela judicial efectiva como derecho fundamental y la protección jurisdiccional. Recuperado de https://www2.uned.es/catortosa/Biblioteca_Digital/Biblio/Valmana/La\%20Tutela.pdf

11.Zambrano Noles, S. (2016). El acceso a la justicia y la tutela judicial efectiva en relación con la seguridad ciudadana en Ecuador. Tla-melaua, 9(39), 58-78. Recuperado http://www.scielo.org.mx/scielo.php?script=sci arttext\&pid=S1870-

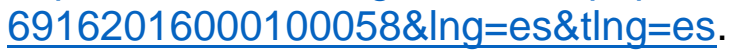

\section{REFERENCIAS CONSULTED}

1. Aldana Zavala, J., \& Isea, J. (2018). Human Rights and Human Dignity. IUSTITIA SOCIALIS, 3 (4), 8-23. Retrieved from http://fundacionkoinonia.com.ve/ojs/index.php/lustitia Socialis/article/view/119 $\underline{101}$

2. Apolín Meza, D. (2007). The right to a process without undue delay. Retrieved from

http://revistas.pucp.edu.pe/index.php/forojuridico/search/search?simpleQuery input=Apol\%C3\%ADn+Meza\&simpleQuery=Apol\%C3\%ADn+Meza\&searchFi eld=authors

3. Celi, I. (2017). Neoconstitutionalism in Ecuador Judicialization of politics or politicization of justice? Recovered from http://repositorio.uasb.edu.ec/bitstream/10644/6072/1/SM213-CeliNeoconstitucionalismo.pdf

4. Constitution of the Republic of Ecuador (2008). Recovered from https://www.oas.org/juridico/mla/sp/ecu/sp ecu-int-text-const.pdf

5. Espín López, I. (2017). The right to a process without undue delay in Spanish judicial practice.

Recovered from https://revistas.um.es/analesderecho/article/view/299461/224441

6. Herrera, S. (2017). Regulatory changes in civil procedure in Ecuador. Recovered from https://www.derechoecuador.com/cambios-normativos-enmateria-de-procedimiento-civil-en-el-ecuador--

7. Le Tourneau, Phillipe (2006). Professional civil responsibility. Legis Bogota Colombia. 
8. Oubiña Barbolla, S. (2016). Improper procrastination EUNOMY Journal of Culture of Legality, 0, 250-264. Recovered from https://erevistas.uc3m.es/index.php/EUNOM/article/view/3062/1759

9. Quintero, M. (2016). The estimatory oath in the General Code of the Process. Recovered from: https://www.ambitojuridico.com/noticias/procesal-ydisciplinario/el-juramento-estimatorio-en-el-codigo-general-del-proceso

10. Valmaña, S. (2018). Effective judicial protection as a fundamental right and jurisdictional protection. Recovered from https://www2.uned.es/catortosa/Biblioteca Digital/Biblio/Valmana/La\%20Tutela.pdf

11.Zambrano Noles, S. (2016). Access to justice and effective judicial protection in relation to citizen security in Ecuador. Tla-Melaua, 9 (39), 58-78. Retrieved from http://www.scielo.org.mx/scielo.php?script=sci arttext\&pid=S1870-

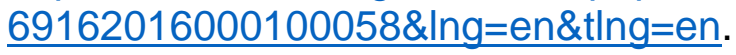

